\title{
Frequency of asthenopia and its association with refractive errors
}

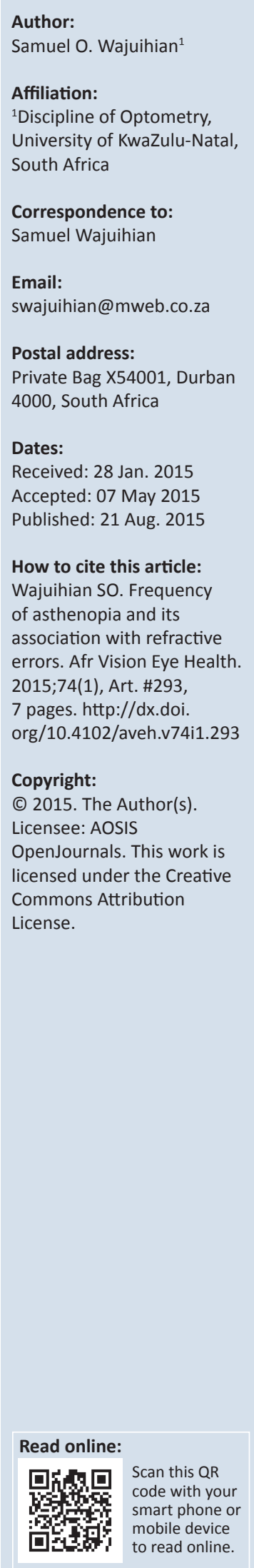

Background: Asthenopia is a common complaint amongst patients who attend eye care settings. Owing to associated discomfort or distress, asthenopia affects efficient reading and performance of near tasks.

Purpose: To study the prevalence of asthenopia and any association with refractive errors in a clinical setting.

Methods: In this cross-sectional practice-based study, the clinic records of 1109 school-aged children (mean age and standard deviation $14.39 \pm 3.39$ years) were analysed. The sample comprised $427(38.5 \%)$ male and $682(61.5 \%)$ female patients between the ages of 6 and 19 years. Refractive errors were classified into various types, and the association between these refractive types and symptoms in asthenopia were explored.

Results: The most common symptom of asthenopia was headaches (40.8\%), of which temporal headaches were the most frequent type (15.7\%). Various symptoms were significantly associated with mainly astigmatism.

Conclusion: Headaches were the most frequent complaint amongst patients who attended the author's optometric practice. Astigmatism was the most frequent cause of asthenopia. Female patients were more likely than male patients to complain of asthenopia, whilst high school students were more likely than primary school children to complain of asthenopia. Further studies to relate asthenopia to binocular anomalies will be relevant in enhancing our understanding of the relationship between asthenopia and vision anomalies.

\section{Introduction}

Asthenopia may be defined as diverse subjective symptoms or distress arising from use of the eyes. ${ }^{1,2,3}$ The term eyestrain has often been used synonymously with asthenopia. ${ }^{2,4}$ Asthenopia often occurs during reading or performance of near point activities. ${ }^{1,5}$ The nonspecific symptoms in asthenopia include eye fatigue, burning, irritation, pain, ache, sore eyes and headache. ${ }^{1,2,3,4}$ The more specific symptoms include photophobia, blur, double vision, itching, tearing, dryness and foreign body sensation. ${ }^{1,4}$ In general, the symptoms of asthenopia pose significant management and treatment challenges, as various anomalies may result in similar symptoms. ${ }^{1,5}$ Similarities in symptoms highlight the need for a proper differential diagnosis. In addition, studying asthenopia is complicated by how various authors define and classify it.

Asthenopia may be classified as internal or external. ${ }^{1}$ The internal type of asthenopia consists of sensations of strain and aches felt inside the eye. ${ }^{1,4}$ The external type consists of sensations of dryness and irritation on the front surface of the eye. Some possible causes of internal asthenopia include uncorrected refractive errors, vergence anomalies such as convergence insufficiency and decompensated heterophoria, as well as accommodative dysfunctions such as accommodative insufficiency or infacility. ${ }^{4,5}$ Uncorrected refractive errors (UREs) are associated with various symptoms of asthenopia. ${ }^{2}$ Uncorrected refractive errors reduce visual efficiency and are aetiological factors in binocular vision anomalies such as convergence insufficiency, accommodative insufficiency, accommodative excess and heterophoria.5,6,7 External types of asthenopia are mainly related to conditions in the viewing environment ${ }^{1,4}$ and are often associated with glare from lighting, altered quality of the viewed image owing to poor contrast, improper optimal gaze angles, flickering stimuli such as computer displays, and dry eye. ${ }^{1}$ The focus of the present study is on refractive error that comprises internal types of asthenopia.

Studies have documented the frequencies of asthenopia in various settings (Table 1). ${ }^{8,9,10,11,12,13}$ However, available reports on the possible associations of asthenopia with refractive errors are few. ${ }^{14,15,16} \mathrm{Abdi}$ and Rydberg ${ }^{14}$ studied asthenopia and orthoptic and ophthalmological functions in 120 Swedish children aged between 6 and 16 years and found a correlation between 
TABLE 1: Frequency (as percentage) of symptoms from various studies.

\begin{tabular}{|c|c|c|c|c|c|c|c|}
\hline Symptoms & Mvitu and Kaimbo & Neugebauer et al. & Dwyer & Alexander et al. & McKay et al. & Westman et al. & Ip et al. \\
\hline Headaches & 47.0 & 84 & 15 & 11.6 & 9.6 & 62.7 & - \\
\hline Ocular pains & 37 & 34 & - & 2 & - & 14.8 & - \\
\hline Near blur or eye strain and tired eye & - & - & 23 & 7.6 & 30.9 & 69.6 & 15.2 \\
\hline Tearing & 24.5 & - & - & 1.2 & - & 3 & - \\
\hline Red eye & 4.3 & 44 & - & 0.8 & - & - & - \\
\hline Photophobia & 20 & 48 & - & 2 & - & - & - \\
\hline Burning sensation & 12.5 & - & - & - & - & - & - \\
\hline Itch & - & - & - & 1 & 9.6 & - & - \\
\hline Grittiness & - & - & - & 1 & - & - & - \\
\hline
\end{tabular}

Note: Please see the full reference list of the article, Wajuihian SO. Frequency of asthenopia and its association with refractive errors. Afr Vision Eye Health. 2015;74(1), Art. \#293, 7 pages. http:// dx.doi.org/10.4102/aveh.v74i1.293, for more information.

hypermetropia and asthenopic symptoms. In a similar study, Abdi et al. ${ }^{15}$ found asthenopia to be significantly correlated with low uncorrected visual acuity and myopia. Ips et al. ${ }^{8}$ studied eye disorders in 6-year-old Australian children with complaints of eyestrain and reported that the prevalence of refractive errors was similar in children without symptoms of eyestrain, although hyperopia was slightly more frequent amongst children with eyestrain $(p=0.0008)$. In addition, Ips et al. $^{8}$ found that children with eyestrain were much more likely (odds ratio [OR] 7.1, confidence interval [CI] 4.6-10.9) to wear spectacles $(n=32 ; 15 \%)$ than children without eyestrain ( $n=29 ; 2.4 \%)$. Hendricks et al. ${ }^{16}$ reported that symptoms of headache showed a statistically significant association with the spherical component of refractive errors.

Asthenopia decreases performance and productivity and affects quality of life. ${ }^{8,17}$ The presence of symptoms is a fundamental aspect of optometric practice, ${ }^{18}$ most patients who attend healthcare facilities do so mainly because they have symptoms. Consequently, evaluation and analysis of patient-reported symptoms in conjunction with clinical measures enables clinicians to arrive at appropriate diagnoses that will guide treatment. The aim of the present study was to determine the frequency and distribution of asthenopia and explore possible associations between asthenopia and refractive errors with data from an optometric practice. Retrospective data are useful in providing large volumes of data that ordinarily would not be available in nonclinical settings. The current study is relevant in differential diagnosis. The hypothesis is that there is no relationship between symptoms of asthenopia and refractive errors.

\section{Methods}

\section{Study design}

This is a retrospective review of 1109 eligible case records of patients seen in the author's optometry practice in Empangeni, South Africa, between January 2010 and December 2012.

\section{Study area and setting}

Empangeni is a town in the uMhlathuze Municipality which is an administrative area in the uThungulu district of KwaZulu-Natal. uMhlathuze is a semi-urban settlement on the north-east coast of the province of KwaZulu-Natal, approximately 170 kilometres north-east of Durban. The N2 highway traverses uMhlathuze Municipality in a northeast direction towards the Swaziland border and south-west towards Durban, and divides Empangeni and Richards Bay. The total area within uMhlathuze is $796 \mathrm{~km}^{2}$ with a population of about $332154 .^{19}$

\section{Study sample}

The participants were consecutive patients; all were black South Africans of the Zulu ethnic group. The patients who attended the optometry practice for routine eye care were residents of the town and surrounding villages. An analysis of the practice's residential demography reveals that patients come from about 25 residential areas including 'townships' and villages. The sample studied consisted of 427 male patients and 682 female. To be included, participants had to be of school-going age (6-19 years of age), in schooling at the time of consultation, developmentally normal children, black and of either gender. Patients' records were excluded from the study if they contained information about any eye disease or systemic conditions such as diabetes mellitus that could have influenced refractive findings. In the author's practice, visual acuity (VA) was routinely assessed using the Snellen chart, and ocular health status was evaluated using the direct ophthalmoscope (Welch Allyn) and the slit lamp biomicroscope (Zeiss SL120/130). Refractive errors (REs) were assessed objectively using an autorefractor (MRK/3100; Huvitz) and streak retinoscope (Welch Allyn). Refractive errors were refined subjectively to the best VA with maximum convex (positive) and minimum concave (negative) lenses, both monocularly and binocularly. Astigmatic power and axis were refined using the Jackson crossed cylinder. Binocular functions such as the near point of convergence, the cover test and von Graefe, stereoacuity, fusional vergences and accommodative functions (amplitude, accuracy and relative) were also routinely performed. For the cases reported, patients' demographic information (gender and age), best corrected VAs, details of subjective refraction and symptoms reported by the patients were obtained. Three different refractive parameters were extracted, namely the spherical, cylindrical and spherical equivalent values, and these subjective refractive findings were analysed. For patients who consulted more than once during the survey period, only the data from the most recent 
visit were recorded (thus, such patients were not included twice).

\section{Diagnostic criteria and classifications of refractive errors}

As an objective of the study was to relate various forms of RE (including types of astigmatism) with symptoms, a broad sub-classification of REs in terms of spheres and cylinders was applied and spherical equivalent refractions (SERs) were not analysed. The criteria for the refractive errors are indicated below and referenced as follows: myopia, ${ }^{20,21,22}$ hyperopia, ${ }^{2,20}$ astigmatism ${ }^{22,23,24,25}$ and emmetropia. ${ }^{2,23}$

\section{Diagnostic criteria for refractive errors \\ Myopia \\ - Mild: from -0.5 to $-3 \mathrm{D}$ \\ - Moderate: from -3.25 to $-6 \mathrm{D}$ \\ - High: $\geq|-6.25 \mathrm{D}|$}

\section{Hyperopia}

- Mild: from 0.5 to $2 \mathrm{D}$

- Moderate: from 2.25 D to $4 \mathrm{D}$

- High: $\geq 4.25$ D.

\section{Astigmatism}

- $\geq|-0.75 \mathrm{D}|$.

To facilitate comparison with various studies, distribution values were also obtained for cylinders $0.25 \mathrm{D}$ and $0.5 \mathrm{D}$. Astigmatism was in negative power notation and was further categorised as:

\section{Magnitude astigmatism:}

- Low astigmatism: from 0.25 to $0.5 \mathrm{D}$

- Moderate astigmatism: from 0.75 to $2 \mathrm{D}$

- High astigmatism: > 2 D.

\section{Axis astigmatism:}

- With-the-rule (WTR) astigmatism included cylinder axes between $1^{\circ}$ and $15^{\circ}$ or $165^{\circ}$ and $180^{\circ}$.

- Against-the-rule (ATR) astigmatism included cylinder axes between $75^{\circ}$ and $105^{\circ}$.

- Oblique astigmatism (OA) was defined as cylinder axes between $16^{\circ}$ and $74^{\circ}$ or $106^{\circ}$ and $164^{\circ}$.

\section{Sphero-astigmatism:}

Simple myopic astigmatism (SMA) occurs when one ray comes into focus in front of the retina and one ray comes into focus on the retina (plano $/ \geq|-0.5 \mathrm{D}|$ ). Compound myopic astigmatism (CMA) occurs when both points of light come into focus in front of the retina $(\geq|-0.5 \mathrm{D}| / \geq|-0.5 \mathrm{D}|)$. Mixed astigmatism (MXA) occurs when one ray comes into focus in front of the cornea and the other ray comes into focus behind the retina $(0.5 \mathrm{D} / \geq|-0.5 \mathrm{D}|)$.

\section{Emmetropia}

- \pm 0.5 D SER, defined as sphere + half cylinder power.

Headache (ocular headache) as used in this study follows the description in the International Classification of Headache $(\mathrm{ICH})^{26}$ which classifies headache associated with refractive errors (HARE) to include recurrent mild headache, frontal, and in the eyes themselves, which fulfills the following criteria: headache and eye pain first develop in close temporal relation to the refractive error, are absent on awakening and aggravated by prolonged visual tasks. In the present study, only complaints of headaches which were mainly related to near point activities (reading, writing, copying and computerbased work) were considered. Some patients also complained of photophobia and light sensitivities. Overall, the headaches were sub-classified according to their locations, to include temporal headache $(\mathrm{TH})$, frontal headache $(\mathrm{FH})$, occipital headache $(\mathrm{OH})$ and general headache $(\mathrm{GH})$. General headaches were diffuse and not localised to a specific region of the head.

\section{Data analysis}

All data were reviewed by the author and analysed by a statistician using the Statistical Package for Social Sciences (SPSS) version 21 (SPSS for Windows, Chicago). Descriptive statistics were presented as means and standard deviation. Distributions of variables were presented using tables. Proportions and corresponding 95\% CIs were presented as an estimate of the prevalence. Pearson correlation coefficients were used to analyse correlations between right and left eye data. Pearson chi-squared tests were used to analyse differences in refractive error in relation to gender, age group and symptoms. In all analyses, a significance level of 0.05 was applied.

\section{Results}

\section{Patients' demographic characteristics}

During the study period, data for the 1109 patients who met the eligibility criteria were included and analysed. They comprised 427 (38.5\%) male and (61.5\%) female subjects, and their ages ranged between 6 and 19 years (mean age $14.4 \pm$ 3.4 years). Data were stratified into 6-12 and 13-19 years age groups, which corresponds with the primary and high school age groups respectively at the time of consultation. More children $(n=780[70.3 \%])$ in the 13-19 years group consulted the optometrist than did those in the 6-12-year-old group $(n=329[29.7 \%])$.

Approximately 860 (77.5\%) of patients had unaided VA of 6/ 6 or better whilst $249(22.5 \%)$ had a VA worse than 6/9. One thousand and seventy-five $(96.9 \%)$ patients had corrected VA of $6 / 6$ or better whilst 34 (3.1\%) had visual impairment. To avoid duplication of the findings which may overestimate statistical significance, and given the high positive correlation between the left and right eyes sphere $(r=0.794, p=0.001)$, only the results for the right eyes were reported. The overall 
$(N=1109)$ mean right eye (RE) for sphere was $-0.33 \pm 1.89$ and mean cylinder power was $-0.5 \pm 0.56$. For male patients $(n=425)$, mean RE was $-0.34 \pm 1.63$ with a minimum of $-14 \mathrm{D}$ and a maximum of $8 \mathrm{D}$. The mean cylinder was $-0.5 \pm 0.63$. For female patients $(n=684), \mathrm{RE}$ sphere was mean $-0.32 \pm$ 2.04 with a minimum of $-25 \mathrm{D}$ and maximum of $8.5 \mathrm{D}$; and mean cylinder power was $-0.5 \pm 0.52$. For the $6-12$-year age group $(n=329)$, mean sphere RE was $-0.51 \pm 2.68$, minimum was $-25 \mathrm{D}$, maximum $8.5 \mathrm{D}$ and mean cylinder power was $-0.52 \pm 0.65$; whilst for the 13-19-year age group $(n=780)$, sphere RE mean was $0.24 \pm 1.43$ minimum $-16 \mathrm{D}$, maximum $3 \mathrm{D}$ and mean cylinder power was $-0.5 \pm 0.52$.

\section{Prevalence of refractive errors}

The prevalence estimates for REs (all) were:

- Myopia ( $\geq \mid-0.5$ D | ) 19.7\% (95\% CI 17.40-21.90)

- Astigmatism ( $\geq$ | -0.75 D I ) $15.4 \%$ (95\% CI 13.30-17.60)

- Hyperopia ( $\geq 0.5$ D) $13.4 \%$ (95\% CI 11.50-15.40)

- Emmetropia ( \pm 0.5 D SER). 50.7 (95\% CI 45.05-52.12).

\section{Subtypes of astigmatism}

The frequencies for various types of astigmatism were:

- Sphero-astigmatism. The frequencies were CMA 115 $(10.4 \%)$, SMA $58(5.2 \%)$, MA $32(2.9 \%)$, and no spheroastigmatism was 904 (81.5\%).

- Axis astigmatism. The frequencies for WTR were 399 (36\%), ATR 264 (23.8\%), OA 252 (22.7\%), and no axis astigmatism was 194 (17.5\%).

- Magnitude astigmatism. The frequencies for LA were $741(66.8 \%)$, MA $140(12.6 \%)$, HA $30(2.7 \%)$, and no magnitude astigmatism was 198 (17.9\%).

\section{Frequency of symptoms}

The frequency of the various symptoms is shown in Table 2. Headache was the most frequent symptom category (40.8\%) and the least prevalent was diplopia (1.9\%). The frequencies of types of headache were: temporal $173(15.7 \%)$, frontal 128 (11.5\%), general 109 (9.8\%) and occipital 42 (3.8\%).

\section{Distribution of symptoms according to gender and age group}

Although all the symptoms were more frequent in female than in male patients, only headaches $(p=0.0003)$, photophobia
TABLE 2: Frequency of asthenopia.

\begin{tabular}{lcc}
\hline Asthenopia & $\boldsymbol{n}$ & Frequency (\%) \\
\hline Headache & 452 & 40.8 \\
Itch & 329 & 29.7 \\
Tearing & 307 & 27.7 \\
Photophobia & 274 & 24.2 \\
Painful/sore & 260 & 23.2 \\
Near blur & 170 & 15.9 \\
Redness & 126 & 11.4 \\
Tired eye & 51 & 4.6 \\
Grittiness & 46 & 4.1 \\
Diplopia & 21 & 1.9 \\
\hline
\end{tabular}

( $p=0.006)$ and redness $(p=0.061)$ were statistically more prevalent in female than in male patients (Table 3). The frequency of headaches in female patients was significantly higher than in male patients in all headache types $(p=0.0003)$, whilst the frequency in the high school age group was higher than in the corresponding primary school age group $(p=0.001)$ (Table 3).

\section{Association of asthenopia and refractive errors}

As shown in Table 4, SMA was significantly associated with frontal headaches $\left(\chi^{2}=17.05, p=0.0001\right)$ whilst CMA was significantly associated with $\mathrm{FH}$ and $\mathrm{GH},(p=0.0001)$. Patients with low and moderate astigmatism had a higher proportion of headaches than those with EMM, HA, LHP and LHP. Low astigmatism was significantly associated with TH, FH and GH ( $p=0.001)$ whilst MA was significantly associated with FH and GH $(p=0.0001)$. Patients with MA had a higher percentage of headaches than those with CMA. For axis astigmatism, ATR, OA and WTR were most associated with $\mathrm{FH}$ and $\mathrm{TH}$.

\section{Discussion}

In the present study of asthenopia and refractive errors in a clinical sample of school age children, the most prevalent symptom type was headache (Table 2) which accounted for about $40.8 \%$ of all symptoms, and the most prevalent type of headache was temporal headaches. Similarly, headaches have been reported to be the most frequent patient-reported symptoms in eye care settings. ${ }^{2,27}$ Overall, the frequency of asthenopia found in the present study (Table 2) is similar to that found in some previous studies but contrasts with

TABLE 3: Frequency ( $n$ and percentage) of symptoms according to gender and age groups.

\begin{tabular}{|c|c|c|c|c|c|c|c|c|c|c|c|c|}
\hline Symptoms & Female & $\%$ & Male & $\%$ & $\chi^{2}$ & $p$ & $6-12$ years & $\%$ & $13-19$ years & $\%$ & $\chi^{2}$ & $p$ \\
\hline Headache & 312 & 44.5 & 140 & 32.3 & 21.09 & 0.003 & 92 & 27.7 & 360 & 44.8 & 34.68 & 0.001 \\
\hline Painful/sore & 158 & 22.5 & 102 & 23.6 & 0.12 & 0.73 & 72 & 21.9 & 188 & 24.1 & 0.59 & 0.45 \\
\hline Tired eye & 30 & 4.3 & 21 & 2.9 & 0.18 & 0.68 & 8 & 2.4 & 43 & 5.5 & 5 & 0.02 \\
\hline Itch & 200 & 28.6 & 129 & 18.4 & 0.13 & 0.72 & 101 & 30.6 & 228 & 29.2 & 0.23 & 0.62 \\
\hline Tearing & 201 & 28.7 & 106 & 24.5 & 2.68 & 0.1 & 87 & 26.4 & 220 & 28.3 & 0.35 & 0.55 \\
\hline Photophobia & 188 & 26.8 & 86 & 19.9 & 7.56 & 0.06 & 39 & 11.9 & 235 & 30.1 & 41.53 & 0.01 \\
\hline Diplopia & 10 & 1.4 & 11 & 2.5 & 1.77 & 0.18 & 1 & 0.4 & 20 & 2.6 & 6.36 & 0.01 \\
\hline Redness & 68 & 9.7 & 58 & 13.4 & 3.51 & 0.01 & 45 & 13.7 & 81 & 10.4 & 2.49 & 0.1 \\
\hline Grittiness & 24 & 3.4 & 22 & 5.1 & 1.82 & 0.18 & 13 & 3.9 & 33 & 4.3 & 0.04 & 0.84 \\
\hline
\end{tabular}

$p$ values $\leq 0.05$ are considered significant. 
TABLE 4: Associations between asthenopia and refractive errors.

\begin{tabular}{lccc}
\hline Symptoms & Refractive variables & $\chi^{2}$ & $\boldsymbol{p}$ \\
\hline $\mathrm{FH}, \mathrm{GH}$ & SMA, CMA & 17.05 & 0.001 \\
TH, FH, GH & LA & 17.05 & 0.001 \\
$\mathrm{FH}, \mathrm{TH}$ & ATR, OA, WTR & 30.77 & 1.18 \\
Itch & MA & 14.86 & 0.01 \\
& LA & 10.94 & 0.09 \\
& OA & 7.80 & 0.001 \\
Tearing & LA & 32.11 & 0.001 \\
& OA, ATR & 18.49 & 0.00 \\
Redness & SMA & 7.84 & 0.05 \\
& ATR, OA & 12.86 & 0.01 \\
Grittiness & OA, ATR & 6.74 & 0.08 \\
& SMA & 11.66 & 0.01 \\
Photophobia & ATR & 8.95 & 0.03 \\
\hline
\end{tabular}

$\mathrm{FH}$, frontal headaches; $\mathrm{GH}$, general headaches; $\mathrm{TH}$, temporal headaches; SMA, simple myopic astigmatism; CMA, compound myopic astigmatism; LA, low astigmatism; ATR, against-the-rule astigmatism; $\mathrm{OA}$, oblique astigmatism, MA, moderate astigmatism. $p$ values $\leq 0.05$ are considered significant.

others (Table 1). The differences in frequency estimates of symptoms reported across studies are influenced by how asthenopia was recorded and the possibilities of omissions inherent in retrospective record studies. Most symptoms of asthenopia were more frequent in female than in male subjects and in high school than in primary school groups. The finding of a preponderance of headaches agrees with other studies. ${ }^{10,28}$ Furthermore, the finding of a higher prevalence of all symptoms in female than male patients suggests that female patients may have more symptoms more frequently than do male patients, or that more female patients than male patients were more likely to report symptoms more frequently. Similarly to the present study, other studies ${ }^{16,29}$ found that more female than male subjects had headaches, and Roth et al. ${ }^{28}$ reported that temporal headaches were most prevalent. Findings on the increased prevalence of headache with advancing age may be related to increased near tasks demand which is usually more prevalent in high school than in primary school age groups..$^{30,31}$ Ocular headache is a reflex pain caused by sustained contraction of the ciliary muscle which in turn causes vascular engorgement that leads to eye ache and headaches. ${ }^{27,32,33}$ The abnormal use of the ciliary muscles acts as a stimulus to reflex headache. ${ }^{27}$ The referred pain presumably results from stimulation of the endings of the nasal branch of the ophthalmic division of the fifth cranial nerve being reflected along other divisions of this nerve. ${ }^{27,32,33}$ Headaches from refractive errors may produce pains in the frontal, bitemporal and occipital regions and at the back of the neck. ${ }^{32}$ Symptoms associated with headaches, such as itching, burning, foreign body sensation or grittiness, pain, sensitivity to light, and excessive tearing, are in most cases manifestations of asthenopia and can be relieved by correcting patients' REs or binocular anomalies. ${ }^{2}$

\section{Asthenopia and refractive errors}

Various symptoms were significantly associated with mainly astigmatism (Table 4) and the proportions of symptoms recorded in the present study compares to the findings from some previous studies (Table 1). Low hyperopia was the most frequent of the hyperopia types (12.8\%) in the present study. Given the high prevalences of near blur and asthenopic symptoms, we occasionally prescribe low plus lenses liberally (in some cases), as preliminary therapy to relieve symptoms of asthenopia and low-grade accommodative problems. Although opinions vary on the need to prescribe low plus lenses to relieve symptoms of asthenopia, ${ }^{34}$ the approach is consistent with other reports regarding the use of low positive lenses in the relief of symptoms of asthenopia., ${ }^{2,14,16}$ Furthermore, hyperopia is the RE that has been associated with poor reading and lowered academic performance..$^{35}$ Even a low magnitude of hyperopia may cause asthenopic symptoms of intermittent blur, headache, fatigue, loss of concentration and inattention in some children, which may be mistaken for a short attention span. ${ }^{35}$ Symptoms of mild itching and sensations of burning could also be associated with hyperopia, astigmatism or binocular anomalies. ${ }^{2}$ In the study by Abdi and Rydberg ${ }^{14}$ on Swedish children aged 6-16 years, a correlation between hyperopia and symptoms of asthenopia was reported. Approximately $98 \%$ of the school children with reduced accommodation, and $94 \%$ of the children with refractive errors and heterophorias, improved with appropriate spherical, cylindrical and prism correction. Also, 93\% were symptom-free 3-6 months after treatment. Ip et al. ${ }^{20}$ reported that hyperopia was more frequent amongst children with eyestrain. In the same study, ${ }^{20} 21.3 \%$ of children with REs complained of eyestrain symptoms, and children with eyestrain were much more likely to wear spectacles than children without these symptoms. The possible reasons for differences in findings amongst the studies by Ip et al.,${ }^{20}$ Abdi and Rydberg ${ }^{14}$ and the present study may be related to differences in study designs, including the criteria applied to define anomalies as well as how asthenopia was recorded and defined. Only astigmatism was significantly associated with headaches and various symptoms (Table 4). This finding agrees with reports from various studies ${ }^{29,32}$ and is consistent with reports that a low magnitude of astigmatism is the most common refractive cause of ocular headaches in young individuals..$^{27,33,34}$ Clinically, in patients with astigmatism, unaided acuity as well as presence of symptoms is dependent upon the type of astigmatism present. ${ }^{2,34}$ Against-the-rule and oblique astigmatism have been suggested to produce more blur and symptoms than WTR; ${ }^{2,34,36}$ this is possibly as a result of clearer vertical image when WTR astigmatism is present. In ATR astigmatism, symptoms of asthenopia may result from small astigmatic errors even if VA is normal. 2,34,36 In oblique astigmatism, compensating for the astigmatic error may significantly improve $\mathrm{VA}^{3}{ }^{34}$ Accordingly, the high prevalence of symptoms of asthenopia may be related to a high prevalence of low-magnitude ATR and WTR astigmatism. Furthermore, in simple or compound myopic astigmatism, no amount of accommodation is able to prevent blurred vision at distance, therefore such errors may cause symptoms of asthenopia at near vision because accommodation may place the circle of least confusion closer to the retina or on the retina, depending on the amount of astigmatism. ${ }^{2,27}$ With high astigmatism, the ciliary muscles may make minimal effort to correct the error and there may be asthenopia. ${ }^{2,27,32}$ However, if the degree of astigmatism is low or moderate, patients make unconscious efforts to 
compensate for the error, ${ }^{32}$ and the ciliary muscle contracts irregularly, causing more asthenopia. ${ }^{32}$ Therefore, a low magnitude of RE, especially astigmatism, often causes more severe headaches than does a high magnitude. ${ }^{2,32,34}$

Another important finding is that some patients who complained of headache also had photophobia. A total of 161 cases $(14.5 \%)$ had headaches associated with photophobia and various authors reported various proportions of photophobia (Table 1). The triad of pain, photophobia and tearing is a response to stimulation of the ophthalmic division of the fifth cranial nerve, ${ }^{2}$ and the process is based on an extensive neural mechanism. ${ }^{37}$ Besides epidemic keratoconjuctivitis and congenital glaucoma, most symptoms of pain may be accompanied by a complaint of increased sensitivity to light. ${ }^{2}$ Asthenopia acts as a trigger to the local axon reflex ${ }^{2}$ and, in an attempt to compensate for the REs, may stimulate sensory nerve endings which results in a local increase in blood supply; ${ }^{2}$ this subsequently manifests as hyperaemia of the conjunctiva or lid. The resulting hyperaemia is responsible for sensations of itching and burning, and causes the individual to rub his or her eyes. ${ }^{2}$

\section{Strengths and limitations}

A major strength of this study is the relatively large sample size and extensively analysis of the relationship between asthenopia and REs which has, to the best of my knowledge, not been reported in the literature. A limitation is that the study is retrospective and may be subject to selection and records bias with a possibility that some information might have been inappropriately recorded. Therefore, the prevalence estimates provided may only be applied in the context of a clinical setting. Findings will enhance our understanding of the frequency of asthenopia and the relationship between asthenopia and REs.

\section{Conclusion}

Astigmatism is the RE most associated with symptoms of asthenopia. The most frequent symptom of asthenopia in school age children attending an optometric practice is headache. Female patients were more likely than male to report symptoms. Students in high school grades were more likely than primary school children to manifest and report symptoms. Future studies that will relate asthenopia and binocular anomalies may be relevant in broadening our knowledge of asthenopia and its associated factors.

\section{Acknowledgements}

\section{Competing interests}

The author declares that he has no financial or personal relationships which might have inappropriately influenced him in writing this article.

\section{References}

1. Sheedy JE. The physiology of eyestrain. J Mod Optics. 2007;54:1333-1341. http:// dx.doi.org/10.1080/09500340600855460
2. Grosvenor T. Primary care optometry. 5th ed. Philadelphia: Butterworth Heinemann Elsevier; 2007.

3. Feldman F, Cooper, J. Assessing the reliability and validity of an asthenopia questionnaire. American Optometric Association. c2014 [cited 2014 Oct 20]. Available from: http://www.aaopt.org/assessing-reliability-and-validityasthenopia-questionnaire

4. Sheedy JE, Hayes J, Engle J. Is all asthenopia the same? Optom Vis Sci. 2003;80:732-739. http://dx.doi.org/10.1097/00006324-200311000-00008

5. Scheiman M, Wick B. Clinical management of binocular vision: Heterophoric, accommodative and eye movement disorders. 3rd ed. Philadelphia, PA: JB Lippincott; 2008.

6. Rutstein RP, Daum KM, Amos JF. Accommodative spasm: A study of 17 cases. J Am Optom Assoc. 1988;59:527-538.

7. Evans BJW. Optometric prescribing for decompensated heterophoria. Optom Pract. 2008;9:63-78.

8. Ip JM, Robaei D, Rochtchina E, Mitchell P. Prevalence of eye disorders in young children with eyestrain complaints. Am J Ophthal. 2006;142:495-497. http:// dx.doi.org/10.1016/j.ajo.2006.03.047

9. Mvitu MM, Kaimbo WK. Manifestations of asthenopia in black subjects. Bull Soc Belge Ophthal. 2003;289:45-49.

10. Alexander JA, Joyes D, Liew C, Omrod M, Wong A. A survey of cases in Sydney optometric practices: Age and sex distributions; symptoms and reasons for consultation. Aust J Optom. 1985;68:133-138.

11. Neugebauer A, Fricke J, Rußmann W. Asthenopia: Frequency and objective findings. Ger J Ophthal. 1992;1:122-124.

12. McKay ME, Woodruff CE, Rumsey JM. Analysis of an optometry school's patient population. J Optom. 2002;27:381-385.

13. Westman M, Liinamaa J. Relief of asthenopic symptoms with orthoptic exercises in convergence insufficiency is achieved in both adults and children. J Optom. 2012;5:62-67. http://dx.doi.org/10.1016/j.optom.2012.03.002

14. Abdi S, Rydberg A. Asthenopia in school children, orthoptic and ophthalmological findings and treatment. Doc Ophthal. 2005;11:65-72. http://dx.doi.org/10.1007/ s10633-005-4722-4

15. Abdi S, Lennerstrand G, Pansell T, Rydberg A. Orthoptic findings and asthenopia in a population of Swedish schoolchildren aged 6 to 16 years. Strabismus. 2008;16:47-55. http://dx.doi.org/10.1080/09273970802020243

16. Hendricks TJW, De Brabandar J, Horst FVD, Hendrikse F. Relationship between habitual refractive errors and headache complaints in school children. Optom Vis Sci. 2007;84:137-143. http://dx.doi.org/10.1097/OPX.0b013e318031b649

17. Moore BD, Augsburger AR, Ciner EB, Cockrell DA, Fern KD, Harb E. Care of the patient with hyperopia. American Optometric Association. 1997 [cited 2013 July 20]. Available from: www.aoa.org/documents/optometrists/CPG-16.pdf

18. Maples WC. Frequency and types of pediatric symptoms in a clinical population. J Optom Vis Dev. 2010;12:74-80.

19. uMhlathuze municipality. n.d. [cited 2015 Aug. 07]. Available from: http://www. umhlathuze.gov.za

20. Ip JM, Robaei D, Kifley A, Wang JJ, Rose KA, Mitchel P. Prevalence of hyperopia and association with eye findings in 6- and 12-year-olds. Ophthalmology. 2008;115:678-685. http://dx.doi.org/10.1016/j.ophtha.2007.04.061

21. Opubiri I, Adio A, Megbelayin E. Refractive error pattern of children in SouthSouth Nigeria: A tertiary hospital study. Sky J Med \& Med Sci. 2013;1:10-14.

22. Quek TPL, Chua CG, Chong CS. Prevalence of refractive errors in teenage high school students in Singapore. Ophthal Physiol Opt. 2004;24:47-55. http://dx.doi. org/10.1046/j.1475-1313.2003.00166.x

23. Naidoo KS, Raghunandan A, Mashige $P$, et al. Refractive errors and visual impairments in African children in South Africa. Invest Ophthal Vis Sci. 2003;44:3764-3770. http://dx.doi.org/10.1167/iovs.03-0283

24. Huynh SC, Kifley A, Rose KA, et al. Astigmatism in 12-year-old Australian children: Comparisons with a 6-year-old population. Invest Ophthalmol Vis Sci. 2007;48:73-82. http://dx.doi.org/10.1167/iovs.06-0263

25. Leung TW, Lam AK, Deng L, Kee CS. Characteristics of astigmatism as a function of age in a Hong Kong clinical population. Optom Vis Sci. 2012;89:984-992. http:// dx.doi.org/10.1097/OPX.0b013e31825da156

26. Headache Classification Committee of the International Headache Society (IHS). The international classification of headache disorders, 3rd ed (beta version). Cephalalgia. 2013;9:629-708.

27. Michaelson IC. Angina capitis. Br J Ophthalmol. 1932;16:202-217. http://dx.doi org/10.1136/bjo.16.4.202

28. Roth Z, Pandolfo K, Simon JW, Zobal-Ratner J. Headache and refractive errors in children. [cited 2014 Jan 12]. Available from: http://oftalmonet.com/wp-content/ uploads/2012/11/Poster-Child-Headaches-ZRoth.pdf

29. Marasini S, Khadka J, Sthapit PR, Sharma R, Prasad BJ. Ocular morbidity on headache ruled out of systemic causes: A prevalence study carried out at a community based hospital in Nepal. J Optomal. 2012;5:68-74. http://dx.doi. org/10.1016/j.optom.2012.02.007

30. Garzia R. The relationship between visual efficiency problems and learning. In: Scheiman $M$, Rouse $M$, editors. Optometric management of learning-related vision problems. St. Louis, MO: Mosby, 2006; pp. 209-280.

31. Bodack M, Chun I, Krumholtz I. An analysis of vision screening data from New York City public schools. Optometry. 2010;81:476-484. http://dx.doi.org/10.1016/j. optm.2010.05.006 
32. Griffith A. The eyes as a cause of headache. Br Med J. 1934;18:296-297. http:// dx.doi.org/10.1136/bmj.2.3841.296

33. Middelholf WF. Four thousand cases of ocular headaches and the different states of refraction connected therewith. [cited 2014 Jan 12]. Available from: http:// europepmc.org/articles/PMC1327040/pdf/taos00106-0095.pdf. 339-347

34. O'Leary C, Evans BJW. Criteria for prescribing optometric interventions: Literature review and practitioner survey. Ophthal Physiol Opt. 2003;23:429-439. http:// dx.doi.org/10.1046/j.1475-1313.2003.00137.x
35. Solan H. Learning disabilities. In: Rosenbloom A, Morgan MW, editors. Principles and practice of pediatric optometry. New York: JP Lippincott; 1990, n.p.

36. Wiggins NP. Daum KM. Visual discomfort and astigmatic refractive errors in VDT use. Optomal Assoc. 1991;62:680-684.

37. Noseda R, Kainz V, Jakubowski M, et al. A neural mechanism for exacerbation of headache by light. Nat Neurosci. 2010;13:239-245. http://dx.doi.org/10.1038/ nn. 2475 